\title{
BMJ Open CanWalk: a feasibility study with embedded randomised controlled trial pilot of a walking intervention for people with recurrent or metastatic
} cancer

\author{
Vicki Tsianakas, ${ }^{1}$ Jenny Harris, ${ }^{1}$ Emma Ream, ${ }^{2}$ Mieke Van Hemelrijck, ${ }^{3}$ \\ Arnie Purushotham, ${ }^{4}$ Lorelei Mucci, ${ }^{5}$ James S A Green, ${ }^{6,7}$ Jacquetta Fewster, ${ }^{8}$ \\ Jo Armes ${ }^{1}$
}

To cite: Tsianakas V, Harris J, Ream E, et al. CanWalk: a feasibility study with embedded randomised controlled trial pilot of a walking intervention for people with recurrent or metastatic cancer. BMJ Open 2017;7:e013719.

doi:10.1136/bmjopen-2016013719

- Prepublication history and additional material is available. To view please visit the journal (http://dx.doi.org/ 10.1136/bmjopen-2016013719).

Received 1 August 2016 Revised 14 December 2016 Accepted 20 December 2016

CrossMark

For numbered affiliations see end of article.

\section{Correspondence to}

Dr Jo Armes;

jo.armes@kcl.ac.uk

\section{ABSTRACT}

Objectives: Walking is an adaptable, inexpensive and accessible form of physical activity. However, its impact on quality of life (QoL) and symptom severity in people with advanced cancer is unknown. This study aimed to assess the feasibility and acceptability of a randomised controlled trial (RCT) of a communitybased walking intervention to enhance QoL in people with recurrent/metastatic cancer.

Design: We used a mixed-methods design comprising a 2-centre RCT and nested qualitative interviews.

Participants: Patients with advanced breast, prostate, gynaecological or haematological cancers randomised 1:1 between intervention and usual care.

Intervention: The intervention comprised Macmillan's 'Move More' information, a short motivational interview with a recommendation to walk for at least $30 \mathrm{~min}$ on alternate days and attend a volunteer-led group walk weekly.

Outcomes: We assessed feasibility and acceptability of the intervention and RCT by evaluating study processes (rates of recruitment, consent, retention, adherence and adverse events), and using end-of-study questionnaires and qualitative interviews. Patientreported outcome measures (PROMs) assessing QoL, activity, fatigue, mood and self-efficacy were completed at baseline and 6, 12 and 24 weeks.

Results: We recruited 42 (38\%) eligible participants. Recruitment was lower than anticipated (goal $n=60$ ), the most commonly reported reason being unable to commit to walking groups $(n=19)$. Randomisation procedures worked well with groups evenly matched for age, sex and activity. By week 24 , there was a $45 \%$ attrition rate. Most PROMs while acceptable were not sensitive to change and did not capture key benefits.

Conclusions: The intervention was acceptable, well tolerated and the study design was judged acceptable and feasible. Results are encouraging and demonstrate that exercise was popular and conveyed benefit to participants. Consequently, an effectiveness RCT is warranted, with some modifications to the intervention

\section{Strengths and limitations of this study}

- The study assessed the feasibility and acceptability of a randomised control trial (RCT) of community-based walking for people with recurrent or metastatic breast, gynaecological, haematological or prostate cancers.

- The intervention made use of freely available walking groups and information, combined with a brief motivational interview and recommendation to walk for at least $30 \mathrm{~min}$ on alternate days and attend a weekly walking group.

- A mixed-methods design, including a two-centre RCT with nested qualitative interviews, was used to assess feasibility and acceptability of the intervention and RCT, and test the utility of different patient-reported outcome measures (PROMs).

- The recruitment centres were London-based limiting generalisability.

- Views of participants from Black and ethnic minority patients were under-represented as the majority of participants were Caucasian and English-speaking.

to include greater tailoring and more appropriate PROMs selected.

Trial registration number: ISRCTN42072606.

\section{INTRODUCTION}

Life expectancy of people with recurrent or metastatic cancer is increasing, but this patient group is at considerable risk of experiencing psychological ${ }^{1}$ and physical health problems. ${ }^{2}{ }^{3}$ Despite growing evidence of significant health benefits, physical activity declines considerably during cancer treatment and remains low afterwards. ${ }^{4}$ 
There is some evidence that maintaining or increasing physical activity in patients with cancer can enhance quality of life (QoL) and well-being as disease progresses. ${ }^{5}{ }^{6}$ However, activity-based interventions are typically supervised and require attendance at specialist facilities, potentially limiting acceptability and economic sustainability. ${ }^{57}$

Brisk walking is an adaptable, inexpensive and effective physical activity ${ }^{8}$ that has been shown to improve QoL, physical functioning and fatigue. ${ }^{5} 7$ It can be undertaken alone or in groups and is not restricted to specific facilities or settings-a factor associated with longer term behaviour change. ${ }^{10}$ However, it is unclear whether walking is acceptable to, or improves physical and psychological well-being of, people with recurrent or metastatic cancer. We therefore assessed the feasibility and acceptability of a community-based walking for people with recurrent or metastatic cancer and randomised controlled trial (RCT). Detailed methods have been published elsewhere. ${ }^{11}$ This article reports on: acceptability and feasibility of the study design and intervention, and provides preliminary evidence of efficacy.

\section{MATERIALS AND METHODS}

\section{Study design and participants}

Feasibility of using RCT methodology to test the effectiveness of the walking intervention was assessed using a sequential, explanatory mixed-methods design ${ }^{12}$ with nested qualitative interviews. The study was undertaken between April and November 2014 in two London NHS Foundation Trusts.

We aimed to recruit at least 60 patients, in order to be able to estimate the SD of the QoL outcome and estimation of the true treatment difference and perform a power calculation and sample size for any future RCT $^{11}$ as recommended for feasibility trials. ${ }^{13}{ }^{14}$ Eligible participants were: (1) $\geq 16$ years; (2) diagnosed with recurrent (advancing) or metastatic breast, colorectal, upper gastrointestinal, gynaecological, haematological, head and neck, melanoma or prostate cancer (specific diagnosis inclusion/exclusion criteria published elsewhere ${ }^{11}$ ).

\section{Recruitment and randomisation}

Initially, healthcare professionals (HCP) approached potential participants; however, because HCP were mostly too busy to identify patients, recruitment was lower than expected; therefore, research staff were assigned to recruit. Participants completed postal questionnaires at baseline (T0), 6 (T1), 12 (T2) and 24 (T3) weeks following recruitment (see figure 1). Additionally, those in the intervention group were asked to record their Walking for Health participation-including date and location of walks attended-on a simple form.

Consenting participants completed baseline questionnaires before randomisation. They were allocated, via an online automated system, to either the control (standard care) or intervention group using minimisation on the basis of age $(\leq 65, \geq 66$ years), sex (male, female) and baseline activity level ( $<1$ hour/week, $\geq 1$ hour/week).

\section{Physical activity intervention}

The 12-week CanWalk intervention aimed to motivate participants to walk for at least $30 \mathrm{~min}$ on alternate days. This target was selected as an acceptable minimum for those who may be sedentary and/or have reduced physical functioning. A 15 min motivational telephone (MI) interview, based on the UK's National Institute for Health and Clinical Excellence (NICE) guidance on promoting physical activity in primary care ${ }^{15} 16$ was provided (by authors VT or JH). Participants were additionally provided with printed material promoting activity (Macmillan Cancer Support (MCS) 'Move More' booklet), ${ }^{17}$ and encouraged to attend a weekly group walk of their choice from the Walking for Health (WfH) programme. WfH is a UK-wide network of free walking groups funded by Macmillan Cancer Support and hosted by The Ramblers, suitable for people living with long-term condition. ${ }^{18} \mathrm{MI}$ is a patient-centred counselling style that enhances an individual's motivation to change. The MI trained researchers assessed the patient's readiness to change and motivation to adhere to the intervention, and used MI techniques to stimulate their use of study materials and make progress towards their own walking goals. ${ }^{19}$ Researchers encouraged participants to plan how they could incorporate the weekly WfH groups alongside walking independently or with family/friends. Interviews were audio recorded with permission and an expert in motivational interviewing provided supervision to the researchers to ensure adherence to operational procedures and the principles of motivational interviewing. ${ }^{11}$ The control group was asked to continue with their usual activities.

\section{Primary outcomes: feasibility measures}

Data were collected on rates of recruitment, consent, retention and adverse events. Reasons for nonparticipation and withdrawal were collected, where possible. Participants completed an end-of-study questionnaire (ESQ) assessing acceptability of CanWalk, randomisation process, study methods and outcome measures. Adherence to CanWalk was evaluated over 7 days at each assessment using a self-report measure. We assessed the feasibility of capturing objective data on walking behaviour by randomly allocating $50 \%$ of the control and intervention groups to use a pedometer (Omron HJ-321-E). Participants were asked to wear them for seven consecutive days at each time-point and complete a usage $\log$ recording their daily step count. Additionally, the intervention group was asked to keep a $\log$ of $\mathrm{WfH}$ walks they undertook. Where possible, reasons for withdrawal from the study were collected.

Ten participants ( 5 per group; 6 men and 4 women; $5>65$ years; 9 White British or Irish) took part in semistructured telephone interviews exploring the 


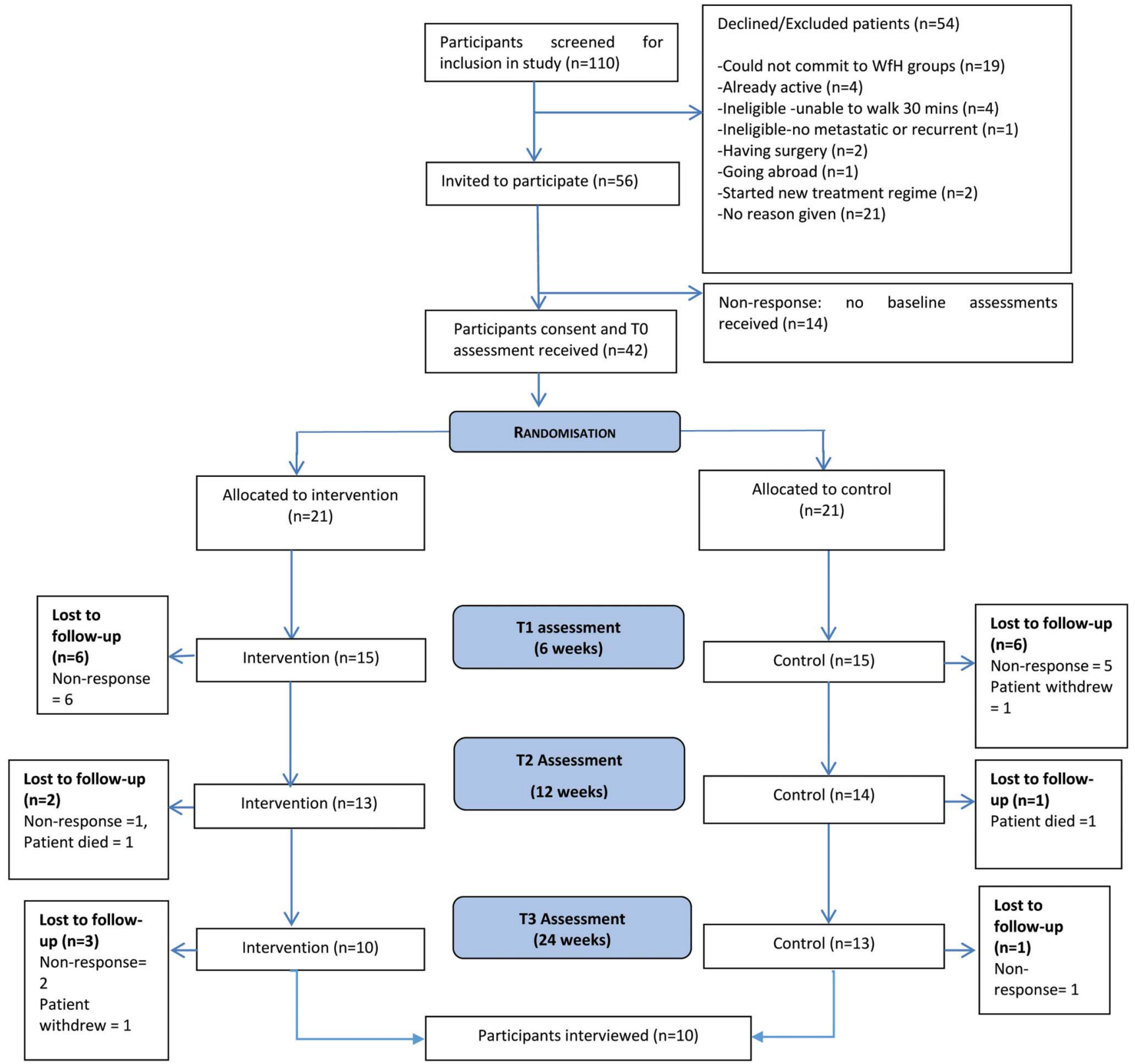

Figure 1 Flow of participants through the study.

acceptability of CanWalk, randomisation process and outcome measures.

\section{Secondary outcomes: between-group outcomes}

Outcome measures for assessing the efficacy of the intervention included QoL (the primary RCT outcome measure), physical activity, mood, exercise self-efficacy, fatigue and performance status (the secondary RCT outcome measures). ${ }^{11}$

\section{Data analysis}

We examined differences between the baseline characteristics of those who completed or withdrew from the study using $\chi^{2}$ and t-tests, as appropriate. Descriptive statistics for all between-group outcome measures are presented, including means (SD), medians (IQR) and frequencies. Cohen's d with $95 \%$ CIs was calculated for effect size. The mean (SD) for the main outcome (QoL) was used to estimate sample size for the effectiveness trial. All data were analysed using SPSS (V.21) or SAS (V.9.4).

Audio recordings of qualitative interviews were transcribed verbatim and analysed using the framework approach. ${ }^{20}$ Descriptive analysis was undertaken of the ESQ and free-text comments integrated with the qualitative data. Findings from the qualitative and quantitative analyses are presented concurrently. The study design is reviewed using the ADePT framework (a process for decision-making after pilot and feasibility trials) ${ }^{21}$ (see online supplementary appendix 1). 
RESULTS

\section{Feasibility assessment}

Recruitment

One hundred and ten people were eligible to participate; $49(47 \%)$ declined-primarily because of work commitments. Although willing to walk on alternate days, they could not commit to a weekly walking group. While initial interest in participating was relatively high (53\%), the recruitment rate was lower $(40 \%)$. Reasons for this are unknown. In interviews, participants reported the randomisation process was acceptable with 21 allocated to each group. While there was little difference in most of the demographic and clinical characteristics between the groups (table 1), almost half of the sample was educated to at least degree level-higher than would be expected in the general population.

\section{Retention}

Nineteen participants $(45 \%)$ withdrew from the study: $12(28 \%)$ between T0 and T1; and $7(17 \%)$ between T2 and T3 (figure 1). Although in general reasons for withdrawal were not provided, two patients were too unwell and two participants died during the study. The only factor associated with withdrawal was higher baseline anxiety $(\mathrm{M}=6.4, \mathrm{SD}=8.1)$ compared with those who completed the study $(\mathrm{M}=4.2, \mathrm{SD}=3.8)(\mathrm{t}(40)=1.16, \mathrm{p}=0.001)$.

\section{Acceptability of outcome measures}

In interviews, participants reported taking 10-40 min to complete outcome measures. All were judged appropriate except the Scottish Physical Activity Questionnaire (SPAQ). Eight participants reported it was repetitive and difficult to complete as illustrated below:

The SPAQ section... a lot of licking my fingers and sticking it in the air, lots of 'think of a number' type thing, it was hard to think. A pre-warning of what was going to be required might have been helpful so you could fill this section in accurately. (3013, male, prostate cancer)

These problems were reflected in data quality, with $45 \%$ completing the daily activity data incorrectly or not at all. Further, insufficient numbers of participants returned the pedometer data at all assessments to permit analysis.

\section{Assessment of methodological components of the trial}

Application of the ADePT framework ${ }^{18}$ suggests most components of the trial protocol worked well (see online supplementary appendix 1 ). The only exception was participants were not recruited from three tumour groups: head and neck, colorectal and skin.

\section{Safety and engagement with the intervention}

No adverse outcomes or events were reported. Views about CanWalk were positive from the ESQ and interviews, although interview data suggested engagement with, and adherence to, WfH group walks varied. Most
$(4 / 5)$ interviewees from the intervention group participated in the WfH group walks plus self-initiated walks. One completed self-initiated walks only.

\section{Hawthorne effect}

During interview, only one participant in the control group reported receiving information about exercise over the course of the study. Yet on the ESQ 9 out of 12 said taking part in this study had stimulated them to undertake more physical activity. Interview findings confirmed this effect in three of the five control group members:

I found it all quite motivating as after filling in the questionnaire and using the pedometer I found that I was more focused on walking. I even did a long walk with the Ramblers which I haven't done in a while. It prompted me to be more fit. I sit less on the sofa now and try to get myself outside. (5020, female, haematological cancer with pedometer)

\section{Participants' views on the intervention}

At 24 weeks, nine participants completed the ESQ and results indicated that most $(n=8)$ found it useful and were satisfied $(n=7)$. Nevertheless, a number of barriers to the intervention were identified at interview. Some participants preferred self-initiated walking, and felt WfH groups, while beneficial for some, did not suit everybody. Reasons included dislike of group activities and accessibility issues. One younger participant who withdrew from the study felt the group walks were more appropriate for older people and decided to continue with self-initiated walks only. Consequently, some interviewees suggested modifying the intervention to offer alternative options to the group walks.

\section{Between-group outcomes}

Primary RCT outcome: QoL

While at baseline, the control group reported lower median FACT-G (Functional Assessment of Cancer Therapy-General) QoL scores than the intervention (53 vs 58, respectively), scores were comparable during follow-up (table 2). Likewise, the FACT-G subscales scores at T1-T3 were relatively high and stable for the intervention and control groups (table 2).

\section{Secondary RCT outcomes}

Comparable results for both groups were also found for the secondary outcomes with median scores remaining relatively stable across assessments. Detailed descriptive analysis of subscale scores provide evidence of some floor or ceiling effects (data not shown). For instance, the EQ-5D (health status) showed a clear floor effect with most participants reporting few symptoms at each time point.

The GPPAQ physical activity index, which includes activity at work, physical exercise and cycling (but not walking), indicated the intervention group was more 
Table 1 Demographic and clinical characteristics of the CanWalk intervention, by study group

\begin{tabular}{|c|c|c|c|}
\hline Demographic or clinical characteristics & Control $(\mathrm{N}=21)$ & Intervention ( $\mathrm{N}=\mathbf{2 1})$ & All \\
\hline \multicolumn{4}{|l|}{ Men } \\
\hline Mean age (SD) & $66.2(10.2)$ & $65(11.7)$ & $65.6(10.8)$ \\
\hline Median age (range) & $68(50-79)$ & $71(40-80)$ & $69(40-80)$ \\
\hline$N$ & $10(48)$ & $11(52)$ & 21 \\
\hline \multicolumn{4}{|l|}{ Women } \\
\hline Mean age (SD) & $58(11.6)$ & $60(12.2)$ & 59 (11.6) \\
\hline Median age (range) & 59 (35-79) & $59(38-78)$ & $59(35-79)$ \\
\hline \multirow[t]{2}{*}{$N$} & $11(52)$ & $10(48)$ & 21 \\
\hline & N (\%) & N (\%) & N (\%) \\
\hline \multicolumn{4}{|l|}{ Ethnic origin } \\
\hline White & $17(81)$ & $17(81)$ & $34(81)$ \\
\hline Black & 4 (19) & $1(5)$ & $5(12)$ \\
\hline Other ethnic groups & 0 & $2(9)$ & $2(4)$ \\
\hline \multicolumn{4}{|l|}{ Marital status } \\
\hline Married & $12(57)$ & $16(80)$ & $28(68)$ \\
\hline Widowed & $0(0)$ & $1(5)$ & $1(2)$ \\
\hline Divorced/separated & $4(19)$ & $1(5)$ & $5(12)$ \\
\hline Single & $5(24)$ & $2(10)$ & $7(17)$ \\
\hline \multicolumn{4}{|l|}{ Employment status } \\
\hline Employed (full or part-time) & $4(20)$ & $6(29)$ & $10(24)$ \\
\hline Sick leave & $3(15)$ & $2(10)$ & $5(12)$ \\
\hline Retired & $10(50)$ & $10(48)$ & 20 (49) \\
\hline Unemployed & 2 (10) & $3(14)$ & 5 (12) \\
\hline Disabled and unable to work & $1(5)$ & $0(0)$ & $1(2)$ \\
\hline \multicolumn{4}{|l|}{ Highest educational attainment } \\
\hline GCSE/O levels or equivalent & $4(20)$ & $5(25)$ & $9(23)$ \\
\hline A levels or equivalent & $1(5)$ & $5(25)$ & $6(15)$ \\
\hline Degree/higher degree & $12(60)$ & 7 (35) & $19(48)$ \\
\hline No formal qualifications & $3(15)$ & $3(15)$ & $6(15)$ \\
\hline Owner-occupier of housing & $18(86)$ & $17(81)$ & $35(83)$ \\
\hline Has any caring responsibilities & $3(15)$ & $1(5)$ & $4(10)$ \\
\hline \multicolumn{4}{|l|}{ Primary cancer } \\
\hline Breast & $4(19)$ & $3(14)$ & $7(17)$ \\
\hline Colorectal & $0(0)$ & $5(1)$ & $1(2)$ \\
\hline Gynaecological & $4(19)$ & $5(24)$ & $9(21)$ \\
\hline Haematological & $4(19)$ & $5(24)$ & $9(21)$ \\
\hline Prostate & $8(38)$ & 7 (33) & $15(36)$ \\
\hline Upper GI & $1(5)$ & $0(0)$ & $1(2)$ \\
\hline \multicolumn{4}{|l|}{ Number of years since diagnosis } \\
\hline Less than 1 year & $6(29)$ & $4(21)$ & $10(25)$ \\
\hline $1-2$ years & $8(38)$ & $6(32)$ & $14(35)$ \\
\hline 3-4 year & $2(10)$ & $2(10)$ & $4(10)$ \\
\hline $5-9$ year & $4(20)$ & $4(21)$ & $8(20)$ \\
\hline 10 years or more & $1(5)$ & $3(16)$ & $4(10)$ \\
\hline \multicolumn{4}{|l|}{ Previous treatments for cancer* } \\
\hline Surgery & $8(38)$ & $8(42)$ & $16(40)$ \\
\hline Radiotherapy & $8(40)$ & $10(53)$ & $18(46)$ \\
\hline Chemotherapy & $14(67)$ & $11(55)$ & $25(61)$ \\
\hline Other & $10(59)$ & $10(53)$ & $25(61)$ \\
\hline Ongoing cancer treatment $†$ & $16(76)$ & $17(81)$ & $33(79)$ \\
\hline Any longstanding illness or disability $\ddagger$ & $9(50)$ & $4(20)$ & $13(31)$ \\
\hline \multicolumn{4}{|l|}{ Main hospital } \\
\hline Site 1 & 15 & 15 & $30(71)$ \\
\hline Site 2 & 6 & 6 & $12(29)$ \\
\hline
\end{tabular}


Table 2 Primary outcome measure for possible randomised controlled trial by assessment time and study group

\begin{tabular}{|c|c|c|c|c|c|}
\hline Quality of life & $\begin{array}{l}\text { Study } \\
\text { group }\end{array}$ & $\begin{array}{l}\text { Baseline } \\
\text { Mean (SD) } \\
\text { Median (IQR) }\end{array}$ & $\begin{array}{l}6 \text { week } \\
\text { Mean (SD) } \\
\text { Median (IQR) }\end{array}$ & $\begin{array}{l}12 \text { week } \\
\text { Mean (SD) } \\
\text { Median (IQR) }\end{array}$ & $\begin{array}{l}24 \text { week } \\
\text { Mean (SD) } \\
\text { Median (IQR) }\end{array}$ \\
\hline \multirow{4}{*}{$\begin{array}{l}\text { FACT-G total } \\
\text { score }^{22}\end{array}$} & \multirow[t]{2}{*}{ Control } & $52(9.1)$ & $51(11.2)$ & $50(7.9)$ & $48(12.7)$ \\
\hline & & $53(11.0)$ & $56(17.5)$ & $52(13.0)$ & $54(20.0)$ \\
\hline & \multirow[t]{3}{*}{ Intervention } & $57(5.2)$ & $56(6.3)$ & $55(5.5)$ & $57(6.9)$ \\
\hline & & $58(4.0)$ & $57(7.25)$ & $56(4.0)$ & $56(10.5)$ \\
\hline $\begin{array}{l}\text { Cohen's d effect } \\
\text { size }(95 \% \mathrm{Cl})\end{array}$ & & $0.67(0.04$ to 1.28$)$ & $0.55(-0.19$ to 1.26$)$ & $0.73(-0.07$ to 1.49$)$ & $0.79(-0.09$ to 1.62$)$ \\
\hline \multirow{4}{*}{$\begin{array}{l}\text { Physical well-being } \\
\text { subscale }\end{array}$} & \multirow[t]{2}{*}{ Control } & $22(5.8)$ & $21(5.7)$ & $22(5.7)$ & $23(4.5)$ \\
\hline & & $24(7.0)$ & $21(10.5)$ & $25(11.0)$ & $24(7.5)$ \\
\hline & \multirow[t]{3}{*}{ Intervention } & $23(4.7)$ & $25(2.4)$ & $25(3.3)$ & $23(4.7)$ \\
\hline & & $26(6.0)$ & $26(4)$ & $26(6.0)$ & $25(4.7)$ \\
\hline $\begin{array}{l}\text { Cohen's d effect } \\
\text { size }(95 \% \mathrm{Cl})\end{array}$ & & $0.19(-0.42$ to 0.79$)$ & $0.91(0.14$ to 1.64$)$ & $0.64(-0.15$ to 1.39$)$ & $0.00(-0.82$ to 0.82$)$ \\
\hline \multirow{4}{*}{$\begin{array}{l}\text { Social and family } \\
\text { well-being subscale }\end{array}$} & \multirow[t]{2}{*}{ Control } & $20(6.1)$ & $19(7.0)$ & $19(6.2)$ & $18(7.3)$ \\
\hline & & $21(11)$ & $21(10.75)$ & $19(10.0)$ & $20(12.5)$ \\
\hline & \multirow[t]{3}{*}{ Intervention } & $22(3.6)$ & $22(3.9)$ & $22(4.0)$ & $22(5.5)$ \\
\hline & & $23(6.0)$ & $23(6.0)$ & $23(4.0)$ & $23(8.0)$ \\
\hline $\begin{array}{l}\text { Cohen's d effect } \\
\text { size }(95 \% \mathrm{Cl})\end{array}$ & & $0.40(-0.22$ to 1.00$)$ & $0.53(-0.21$ to 1.24$)$ & $0.57(-0.22$ to 1.32$)$ & $0.61(-0.26$ to 1.43$)$ \\
\hline \multirow{4}{*}{$\begin{array}{l}\text { Emotional } \\
\text { well-being subscale }\end{array}$} & \multirow[t]{2}{*}{ Control } & $17(5.2)$ & $18(4.4)$ & $19(3.8)$ & $20(3.3)$ \\
\hline & & $16(8.0)$ & $19(5.3)$ & $19(6.0)$ & $20(6.5)$ \\
\hline & \multirow[t]{3}{*}{ Intervention } & $17(5.5)$ & $20(3.6)$ & $20(3.7)$ & 18 (3.8) \\
\hline & & $19(7.0)$ & $20(4.0)$ & $21(6.0)$ & $18(6.2)$ \\
\hline $\begin{array}{l}\text { Cohen's d effect } \\
\text { size }(95 \% \mathrm{Cl})\end{array}$ & & $0.00(-0.60$ to 0.60$)$ & $0.50(-0.24$ to 1.21$)$ & $0.27(-0.50$ to 1.02$)$ & $-0.57(-1.39$ to 0.29$)$ \\
\hline \multirow{4}{*}{$\begin{array}{l}\text { Functional } \\
\text { well-being subscale }\end{array}$} & \multirow[t]{2}{*}{ Control } & $18(5.0)$ & $17(6.6)$ & $19(6.5)$ & $21(7.6)$ \\
\hline & & $19(9.0)$ & $17.5(10.3)$ & $19(11.0)$ & $23(14.5)$ \\
\hline & \multirow[t]{2}{*}{ Intervention } & $21(6.5)$ & $23(5.6)$ & $23(4.7)$ & $23(5.3)$ \\
\hline & & $23(13.0)$ & $26(8.0)$ & $23(7.0)$ & $25(8.0)$ \\
\hline $\begin{array}{l}\text { Cohen's d effect } \\
\text { size }(95 \% \mathrm{Cl})\end{array}$ & & $0.52(-0.11$ to 1.12$)$ & $0.98(0.20$ to 1.71$)$ & $0.70(-0.10$ to 1.46$)$ & $0.30(-0.54$ to 1.12$)$ \\
\hline
\end{tabular}

FACT, Functional Assessment of Cancer Therapy-General.

active at all assessments than the control, and physical activity levels for both groups declined over the study period. However, the GPPAQ item which measures walking activity indicated that the proportion of participants doing at least 3 hours of walking a week increased in both groups (table 3 ).

In contrast, interview data showed that the intervention group felt that they benefited in terms of physical, emotional and psychological, social well-being and lifestyle changes (see table 4 for illustrative quotes). Most participants reported being previously active and understood the benefits of being more physically active. On the ESQ 7 out of 10 of the intervention group reported they had set physical activity goals at baseline which they achieved by 24 weeks. In interviews, all participants in the intervention group and three out of five in the control group reported being more active by 24 weeks.

Well-being and lifestyle benefits, such as weight loss, also motivated participants to increase the amount they walked. They spoke about how it improved their overall QoL and helped them maintain a positive attitude towards their illness. Many participants in the intervention group spoke of the social benefits of participating in the WfH groups (table 4 for illustrative quotes).

\section{DISCUSSION}

This study aimed to assess the feasibility and acceptability of an RCT of a community-based walking programme in people with recurrent/metastatic cancer. Our results indicate that most self-initiated walks were acceptable, though some reported being unable to commit to the WfH groups regularly, largely due to work commitments. The CanWalk intervention, based on the UK's NICE (National Institute for Healthcare and Clinical Excellence) guidance for promoting physical activity, ${ }^{15} 28$ includes active components identified as helping individuals change their behaviour, ${ }^{16}$ such as goal setting, planning and social support. However, it is possible that including more monitoring and tailored feedback could be beneficial and could be offered remotely through the use of apps and/or websites. This is supported by comments from participants from the intervention and support groups, indicating they found that completing 
Table 3 Secondary outcome measures possible randomised controlled trial by assessment time and study group

\begin{tabular}{|c|c|c|c|c|c|}
\hline Measures & Study group & $\begin{array}{l}\text { Baseline } \\
\text { Mean (SD) } \\
\text { Median (IQR) }\end{array}$ & $\begin{array}{l}6 \text { weeks } \\
\text { Mean (SD) } \\
\text { Median (IQR) }\end{array}$ & $\begin{array}{l}12 \text { weeks } \\
\text { Mean (SD) } \\
\text { Median (IQR) }\end{array}$ & $\begin{array}{l}24 \text { weeks } \\
\text { Mean (SD) } \\
\text { Median (IQR) }\end{array}$ \\
\hline \multirow[t]{4}{*}{ Global fatigue score 23} & \multirow[t]{2}{*}{ Control } & $36(21.6)$ & $35(22.0)$ & $32(21.9)$ & $28(24.5)$ \\
\hline & & $31(28.0)$ & $43(37.0)$ & $26(40.0)$ & $18(47.5)$ \\
\hline & \multirow[t]{2}{*}{ Intervention } & $32(22.3)$ & $18(15.9)$ & $23(17.3)$ & $29(19.1)$ \\
\hline & & $33(43.0)$ & $15(24.0)$ & $25(33.0)$ & $31(24.7)$ \\
\hline Cohen's d effect size $(95 \% \mathrm{Cl})$ & & $-0.18(-0.78$ to 0.43$)$ & $-0.89(-1.61$ to -0.11$)$ & $-0.45(-1.20$ to 0.32$)$ & $0.04(-0.78$ to 0.87$)$ \\
\hline \multirow{4}{*}{ Exercise self-efficacy $^{24}$} & \multirow{2}{*}{ Control } & $28(6.0)$ & $29(5.5)$ & $29(4.6)$ & $29(5.0)$ \\
\hline & & $29(9.0)$ & $29(6.0)$ & $30(6.0)$ & $28(4.5)$ \\
\hline & \multirow[t]{2}{*}{ Intervention } & $30(6.0)$ & $33(5.2)$ & $33(5.4)$ & $34(4.6)$ \\
\hline & & $31(8.0)$ & $33(10.0)$ & $36(10.0)$ & $34(8.25)$ \\
\hline Cohen's d effect size $(95 \% \mathrm{Cl})$ & & $0.33(-0.28$ to 0.94$)$ & $0.75(-0.01$ to 1.71$)$ & $0.80(-0.01$ to 1.56$)$ & $1.01(0.10$ to 1.84$)$ \\
\hline \multirow[t]{4}{*}{ Stress total score ${ }^{25}$} & \multirow[t]{2}{*}{ Control } & $9(9.0)$ & $8(9.1)$ & $4(4.7)$ & $9(9.5)$ \\
\hline & & $6(12.0)$ & $5(9.5)$ & $4(8.0)$ & $8(0-26)$ \\
\hline & \multirow[t]{2}{*}{ Intervention } & $8(9.7)$ & $4(5.1)$ & $5(5.9)$ & $3(3.6)$ \\
\hline & & $2(18.0)$ & $4(6.0)$ & $4(10.0)$ & $2(6.0)$ \\
\hline Cohen's d effect size $(95 \% \mathrm{Cl})$ & & $-0.11(-0.71$ to 0.50$)$ & $-0.54(-1.26$ to 0.20$)$ & $0.19(-0.57$ to 0.94$)$ & $-0.76(-1.59$ to 0.11$)$ \\
\hline \multirow[t]{4}{*}{ Anxiety total score 25} & \multirow[t]{2}{*}{ Control } & $6(5.3)$ & $5(5.4)$ & $3(3.1)$ & $6(8.3)$ \\
\hline & & $6(6.0)$ & $4(6.5)$ & $2(6.0)$ & $2(9.0)$ \\
\hline & \multirow[t]{2}{*}{ Intervention } & $4(7.1)$ & 2 (3.3) & $4(6.0)$ & $2(2.7)$ \\
\hline & & $2(4.0)$ & $0(2.0)$ & $2(4.0)$ & $0(5.0)$ \\
\hline Cohen's d effect size $(95 \% \mathrm{Cl})$ & & $-0.32(-0.92$ to 0.30$)$ & $-0.67(-1.39$ to 0.08$)$ & $0.21(-0.55$ to 0.96$)$ & $-0.60(-1.42$ to 0.26$)$ \\
\hline \multirow{4}{*}{ Depression total score ${ }^{25}$} & \multirow[t]{2}{*}{ Control } & $8(7.2)$ & $8(8.4)$ & $5(6.5)$ & $8(9.0)$ \\
\hline & & $6(11.0)$ & $2(14.0)$ & $2(9.0)$ & $2(13.0)$ \\
\hline & \multirow[t]{2}{*}{ Intervention } & $8(10.1)$ & $3(4.9)$ & $4(5.9)$ & $4(5.7)$ \\
\hline & & $6(15.0)$ & $0(4.0)$ & $0(6.0)$ & $2(9.0)$ \\
\hline Cohen's d effect size $(95 \% \mathrm{Cl})$ & & $0.00(-0.60$ to 0.60$)$ & $-0.73(-1.43$ to 0.03$)$ & $-0.16(-0.91$ to 0.60$)$ & $-0.52(-1.33$ to 0.34$)$ \\
\hline \multirow{4}{*}{ EQ-5D score ${ }^{26}$} & \multirow[t]{2}{*}{ Control } & $2(0.66)$ & $2(0.5)$ & $2(0.6)$ & $1(0.5)$ \\
\hline & & $2(1.0)$ & $2(1.0)$ & $1(1.0)$ & $1(0.7)$ \\
\hline & \multirow[t]{2}{*}{ Intervention } & $1(0.52)$ & $1(0.4)$ & $1(0.4)$ & $1(0.4)$ \\
\hline & & $1(1.0)$ & $1(0.8)$ & $1(1.0)$ & $1(0.6)$ \\
\hline Cohen's d effect size $(95 \% \mathrm{Cl})$ & & $-1.68(-2.35$ to -0.95$)$ & $-2.21(-3.05$ to -1.25$)$ & $-1.95(-2.80$ to -0.98$)$ & $0.00(-0.82$ to 0.82$)$ \\
\hline \multirow[t]{4}{*}{ EQ-VAS Your health today score out of $100^{26}$} & \multirow[t]{2}{*}{ Control } & $72(22.6)$ & $82(12.1)$ & $76(26.4)$ & $79(19.6)$ \\
\hline & & $80(40)$ & $78(20.3)$ & $90(41.5)$ & $80(31.0)$ \\
\hline & \multirow[t]{2}{*}{ Intervention } & $75(17.0)$ & $84(12.8)$ & $78(18.1)$ & $81(14.9)$ \\
\hline & & $70(30)$ & $85(20.0)$ & $80(28.8)$ & $80(25.0)$ \\
\hline Cohen's d effect size $(95 \% \mathrm{Cl})$ & & $0.15(-0.46$ to 0.75$)$ & $0.16(-0.56$ to 0.87$)$ & $0.09(-0.67$ to 0.84$)$ & $0.17(-0.67$ to 0.99$)$ \\
\hline \multirow[t]{3}{*}{ Active/moderately active 27} & & $\mathbf{N}(\%)$ & $\mathbf{N}(\%)$ & $\mathbf{N}(\%)$ & $\mathbf{N}(\%)$ \\
\hline & Control & $2(10)$ & 0 & $1(7)$ & 0 \\
\hline & Intervention & $6(29)$ & $5(34)$ & $4(31)$ & $2(20)$ \\
\hline \multirow[t]{2}{*}{ Walked $\geq 3$ hours in last 7 days ${ }^{27}$} & Control & $9(47)$ & $7(54)$ & $11(79)$ & 9 (82) \\
\hline & Intervention & $9(43)$ & $9(70)$ & $7(58)$ & $5(62)$ \\
\hline
\end{tabular}


Table 4 Participants views and experiences of the intervention

\begin{tabular}{|c|c|}
\hline Theme & Illustrative comments \\
\hline Physical benefits & $\begin{array}{l}\text { Its praises should be sung more widely, it really would deserve that. It had a revolutionary } \\
\text { effect on me. I'm a walking bore now I'm afraid! It was just the right thing at just the right time } \\
\text { for me. I think more about walking now, I think can I walk there instead of catching the bus. It's } \\
\text { a fairly painless way of keeping weight down while still eating a little bit of what you enjoy.... } \\
\text { ( } 3022 \text { male, prostate cancer no pedometer) } \\
\text { I have walked ever since at least } 3 \text { days a week. This study has stimulated me. I drop my } \\
\text { daughter off at school then go with the dog for a long walk. I have noticed the difference } \\
\text { physically. I am back on chemo now and have noticed differences with side effects compared } \\
\text { to last year. Last year I had oedema which I don't this time and I just feel a lot fitter this time } \\
\text { round. In general, I have a little more stamina than before }(5016, \text { male, haematological cancer, } \\
\text { with pedometer) }\end{array}$ \\
\hline $\begin{array}{l}\text { Emotional/psychological } \\
\text { well-being }\end{array}$ & $\begin{array}{l}\text { I would definitely recommend it, particularly to people who are not actively sporty or for } \\
\text { sedentary people. Being diagnosed with cancer is a pretty devastating thing and being told its } \\
\text { terminal is even more devastating and when I'm on the walks I forget about the cancer, they } \\
\text { have helped me enormously by keeping me physically fit and keeping me well but also } \\
\text { mentally. I bang on a lot less to those around me about dying than I used to. And that's got to } \\
\text { be good for them as well ( } 3022, \text { male prostate cancer) }\end{array}$ \\
\hline Social benefits & $\begin{array}{l}\text { I have been doing Nordic walking }[\mathrm{WfH}] \text { at least once a week-it has made a huge difference } \\
\text { to me physically and mentally. It makes me do more than I would if I was walking on my own, } \\
\text { I have met all sorts of people and as I live on my own it's great being out and meeting other } \\
\text { people (4065, female gynaecological cancer with pedometer) }\end{array}$ \\
\hline $\begin{array}{l}\text { Well-being and lifestyle } \\
\text { benefits }\end{array}$ & $\begin{array}{l}\text { The impact has been immense! Gave me the motivation to not only increase walking activity } \\
\text { from minutes to } 3-4 \text { hours per week but also to reduce weight to desired } 77-80 \mathrm{~kg} \text { by altering } \\
\text { diet/reducing sweets/sugars. Great boost to morale-no longer dwell on being terminal-just on } \\
\text { getting on with making life as enjoyable as possible, greatly helped by friends made on regular } \\
\text { 'walks for life' (3022, male, prostate cancer) }\end{array}$ \\
\hline Barriers to group walks & $\begin{array}{l}\text { There was only one walk I could find locally that lasted more than } 30 \text { min and seemed to cover } \\
\text { a reasonable distance. I turned up to meet and they were meeting in the tea room. I know this } \\
\text { sounds a bit ridiculous but I wanted to see who was in the group rather than going straight in. It } \\
\text { seemed that everyone in the group was quite a bit older than me, and they spent the first } \\
20 \text { min of the walking time drinking tea in the cafe. When they moved off they were walking } \\
\text { quite slowly. I'm not criticising the validity of these social group walks but I was looking for } \\
\text { something a bit more energetic, and with people closer in age to me ( } 8003 \text {, male, colorectal } \\
\text { cancer) }\end{array}$ \\
\hline
\end{tabular}

the outcome measures stimulated them to increase their physical activity levels.

Key elements of feasibility testing have been identified by Bowen et $a l^{29}$ and are used (highlighted in bold) here to evaluate whether the CanWalk intervention warrants further investigation. A central focus to our study involved estimating demand for the intervention. Forty per cent of those eligible to participate in the study consented. This is comparable to recruitment rates reported in similar studies, ${ }^{30}$ and not unexpected in a population comprising people with advanced cancer. Almost a third withdrew within 6 weeks, which is higher than found in previous research; however, these studies included those with early stage cancer $^{31}$ or had shorter follow-ups (4 weeks). ${ }^{30} 32$ Our preliminary evidence indicated an association between withdrawal and higher baseline anxiety. This warrants further exploration and consideration of ways the intervention could be made more appealing and acceptable for people with symptoms of anxiety, perhaps through a buddy system or by enhancing the motivational interview component with 'booster' follow-up sessions.
This feasibility study also explored the implementation of the study and intervention. Importantly, based on the study data, a power calculation was performed for target recruitment for a future trial. However, the proposed recruitment estimate was not feasible within the timeframe; despite extending recruitment and widening the eligibility criteria to include other diagnoses.

For clinicians to change their practice, they require evidence of the practicality of the interventions, ie, that they can be delivered within existing means and resources. ${ }^{29}$ The complementary components of the intervention promoted physical activity. The researchers spent $\sim 20 \mathrm{~min}$ per person delivering CanWalk. This suggests that if the intervention proves effective, it could be sufficiently brief for delivery by HCP in the clinical setting.

Limited-efficacy testing gives an indication of the likely impact of the intervention, although not the primary aim of a feasibility study. Results suggest few differences between groups across the outcome measures at any time point. Arguably, this inability to detect change could be attributed to the small sample size, as the pilot 
study was insufficiently powered to detect subtle differences. Further, similar to other studies, ${ }^{30} 3233$ contamination may have occurred while assessing activity levels using outcome measures which reportedly stimulated all participants to engage in physical activity. Likewise, participants highlighted that using pedometers with both groups had a similar effect. This suggests an alternative method of assessing walking behaviour is required.

Detailed descriptive evaluation of the performance of the outcome measures suggests that while being reliable, some of the measures may not be sensitive to change as they demonstrated floor/ceiling effects. Moreover, feedback from the ESQ and interviews suggested social support was a key perceived benefit of participating in the WfH walks, but this was not reflected in the FACT-G social well-being subscale scores. However, this may be because it focuses entirely on support from family and relatives and so would not be sensitive to benefits from making wider social contacts. It will therefore be important to include a brief social support and engagement measure (such as the Duke-Social Support Questionnaire $)^{34}$ in future research. Our findings demonstrate the importance of pilot testing questionnaires. Many participants reported the SPAQ was timeconsuming and confusing suggesting a need to use other measures of physical activity for both measuring adherence to the intervention and outcomes. Pedometer data were often not returned, thus alternative methods for measuring the intensity, duration and frequency of physical activity in any future study are recommended. While accelerometers have been used in previous studies, they often require expert knowledge to interpret and analyse results, so the use of off-the-shelf wearable technologies may offer an alternative and more cost-effective approach. ${ }^{35}$

Some participants were, from the outset, already active which contributed to difficulty in detecting between-group changes. Thus, it may be preferable to only recruit people who are judged to be inactive. However, this will reduce the number eligible to participate and exclude people who, although active, wish to increase the amount they walk.

Based on the study findings, a number of adaptations are proposed for a future study, including the refinement of the study samples to include different comparison groups, for example, a tailored CanWalk intervention and written information only group. Furthermore, it will be important to ensure that outcome measures used match the benefits reported by participants in the interviews, such as feeling fitter and having more stamina (eg, functional walking/fitness tests such as incremental shuttle walk or 6 min walk test), being less inactive (eg, measure of sedentary behaviour), weight loss (eg, weight, body mass index, hip to waist ratio) and symptom control.

Several limitations were identified in the study. The recruitment centres were London-based, thus limiting generalisability. Although we were able to collect reasons for non-participation, unfortunately, we were not able to collect data on the demographic or clinical characteristics of those who declined participation. Further, the qualitative sample was small, limiting the extent of indepth analysis of participants' perceptions and experiences. Another limitation is that the views of participants from Black and minority ethnic groups are underrepresented as the study recruited primarily Caucasian participants and English speakers.

\section{CONCLUSIONS}

This study investigated the feasibility and acceptability of undertaking an RCT of a community-based walking programme to enhance QoL in people with recurrent or metastatic cancer. Results are encouraging and demonstrate that exercise was popular and conveyed benefit to participants. However, further exploration of the intervention is required to refine and understand its components and enhance its capacity to create measurable change.

\section{Author affiliations}

${ }^{1}$ Florence Nightingale Faculty of Nursing and Midwifery, Kings College London, Kings Health Partners, London, UK

${ }^{2}$ Faculty of Health and Medical Sciences, University of Surrey, School of Health Sciences, Guildford, UK

${ }^{3}$ Division of Cancer Studies, Cancer Epidemiology Group, King's College London, Kings Health Partners, London, UK

${ }^{4}$ Division of Cancer Studies, Cancer Epidemiology Group, King's College London, Guys Hospital, UK

${ }^{5}$ Department of Epidemiology, Harvard TH Chan School of Public Health, Boston, Massachusetts, USA

${ }^{6}$ Department of Urology, Whipps Cross University Hospital, Barts Health NHS Trust, London, UK

${ }^{7}$ London South Bank University, London, UK

${ }^{8}$ Wellbeing and Support Department, Macmillan Cancer Support, Physical Activity Team, London, UK

Twitter Follow Vicki Tsianakas, Jenny Harris and Jo Armes @CancerCareKCL

Acknowledgements The authors would also like to thank the research project team and steering group and all research partners involved at Guy's and St

Thomas' Hospital, King's College Hospital, Macmillan Cancer Support and The Ramblers. The authors would also like to thank Karen Robb from NHS England for her expertise and Victoria Nnatuanya, the PPI representative from the South East London Consumer Research Panel based at BRC in Guys Hospital and lan Noonan for providing expert advice during the course of the study, as well as study participants.

Contributors VT and JH recruited participants and were responsible for day-to-day study coordination, delivery of the intervention and drafted the manuscript. JA is the study chief investigator and provided the concept, hypotheses, study design and methods, recruitment of participants, is responsible for the overall study management and drafted and critically revised the manuscript. ER, MVH, AP, LM, JSAG and JF participated in the design of the study, critically revised the protocol and the manuscript. All authors read and approved the final manuscript.

Funding This work was supported by Dimbleby Cancer Care. The full study report was submitted to the funding body_Dimbleby Cancer Care-in 2015.

Disclaimer The study was designed and conceived independently of the study funder and sponsor, and neither had any role in the collection, management, analysis, interpretation of the data or writing of the full report.

Competing interests None declared. 
Ethics approval Ethical approval was gained from the National Research Ethics Service (Ref. 13/NW/0860) and research governance approval granted by both NHS Trusts.

Provenance and peer review Not commissioned; externally peer reviewed.

Data sharing statement No additional data are available.

Open Access This is an Open Access article distributed in accordance with the Creative Commons Attribution Non Commercial (CC BY-NC 4.0) license, which permits others to distribute, remix, adapt, build upon this work noncommercially, and license their derivative works on different terms, provided the original work is properly cited and the use is non-commercial. See: http:// creativecommons.org/licenses/by-nc/4.0/

\section{REFERENCES}

1. Mehnert A, Brähler $\mathrm{E}$, Faller $\mathrm{H}$, et al. Four-week prevalence of mental disorders in patients with cancer across major tumor entities. J Clin Oncol 2014;32:3540-6.

2. National Cancer Intelligence Network: recurrent and metastatic breast cancer. Data collection project. Pilot report. 2012. http://www. ncin.org.uk/view?rid=1043 (accessed 27 Jun 2016).

3. Cramarossa G, Chow E, Zhang L, et al. Predictive factors for overall quality of life in patients with advanced cancer. Support Care Cancer 2013;21:1709-16.

4. Javaheri PA, Nekolaichuk C, Haennel R, et al. Feasibility of a pedometer-based walking program for survivors of breast and head and neck cancer undergoing radiation therapy. Physiother Can 2015;62:205-13.

5. Lowe SS, Watanabe SM, Courneya KS. Physical activity as a supportive care intervention in palliative cancer patients: a systematic review. J Support Oncol 2009;7:27-34

6. Beaton R, Pagdin-Friesen W, Robertson C, et al. Effects of exercise intervention on persons with metastatic cancer: a systematic review. Physiother Can 2009;61:141-53.

7. Lowe SS, Watanabe SM, Baracos VE, et al. Physical activity interests and preferences in palliative cancer patients. Support Care Cancer 2010;18:1469-75.

8. Ogilvie D, Foster CE, Rothnie $\mathrm{H}$, et al. Interventions to promote walking: systematic review. Br Med J 2007;334:1204.

9. Chen HM, Tsai CM, Wu YC, et al. Randomised controlled trial on the effectiveness of home-based walking exercise on anxiety, depression and cancer-related symptoms in patients with lung cancer. Br J Cancer 2015;112:438-45.

10. Hillsdon M, Thorogood M, White I, et al. Advising people to take more exercise is ineffective: a randomized controlled trial of physical activity promotion in primary care. Int $J$ Epidemiol 2002;31:808-15

11. Harris J, Tsianakas V, Ream E, et al. CanWalk: study protocol for a randomized feasibility trial of a walking intervention fo people with recurrent or metastatic cancer. Pilot Feasibility Stud 2015;1:7.

12. Bryman A. Integrating quantitative and qualitative research: how is it done? Qual Res 2006;6:97-113.

13. Julious SA. Sample size of 12 per group rule of thumb for a pilot study. Pharm Stat 2005;4:287-91.

14. Sim J, Lewis M. The size of a pilot study for a clinical trial should be calculated in relation to considerations of precision and efficiency. $J$ Clin Epidemiol 2012;65:301-8.
15. National Institute for Healthcare and Clinical Excellence (NICE). Physical activity, 2012. https://www.nice.org.uk/advice/lgb3/chapter/ Introduction (accessed 27 Jun 2016).

16. National Institute for Healthcare and Clinical Excellence (NICE). Behaviour change: individual approaches, 2014. https://www.nice. org.uk/guidance/PH49 (accessed 27 Jun 2016).

17. Macmillan: move more, 2011. https://be.macmillan.org.uk/be/ p-19569-move-more-your-complete-guide-to-becoming-more-active. aspx (accessed 27 Jun 2016).

18. The Ramblers: walking for health, 2015. https://www. walkingforhealth.org.uk/ (accessed 27 Jun 2016).

19. Rollnick S, Butler CC, Kinnersley $P$, et al. Competent novice: motivational interviewing. BMJ 2010;340:1242-5.

20. Ritchie J, Spencer LS. Qualitative data analysis for applied policy research. London: Routledge, 2014;173-94.

21. Bugge $\mathrm{C}$, Williams $\mathrm{B}$, Hagen $\mathrm{S}$, et al. A process for decision-making after pilot and feasibility trials (adept): Development following a feasibility study of a complex intervention for pelvic organ prolapse. Trials 2013;14:353.

22. Cella DF, Tulsky DS, Gray G, et al. The Functional Assessment of Cancer Therapy scale: development and validation of the general measure. J Clin Oncol 1993;11:570-9.

23. Mendoza TWX, Cleeland CS, Morrissey M, et al. Brief Fatigue Inventory, 2016. http://www.mdanderson.org/education-andresearch/departments-programs-and-labs/departments-anddivisions/symptom-research/symptom-assessment-tools/ brief-fatigue-inventory-bfi.html (accessed 27 Jun 2016).

24. Kroll T, Kehn M, Ho PS, et al. The SCI exercise self-efficacy scale (ESES): development and psychometric properties. Int J Behav Nutr Phys Act 2007;4:34

25. Lovibond S, Lovibond PF. Manual for the depression anxiety stress scales. Psychology Foundation of Australia, 1996.

26. NHS England Research Foundation: EQ-5D, 2016. http://www. euroqol.org/about-eq-5d.html (accessed 27 Jun 2016).

27. Public Health England. The General Practice Physical Activity Questionnaire (GPPAQ), 2009. http://www.erpho.org.uk viewResource.aspx?id=18813 (accessed 27 Jun 2016).

28. National Institute for Healthcare and Clinical Excellence [NICE] Walking and cycling, 2013. https://www.nice.org.uk/advice/lgb8 (accessed 27 Jun 2016).

29. Bowen DJ, Kreuter M, Spring B, et al. How we design feasibility studies. Am J Prev Med 2009;36:452-7.

30. Rummans TA, Clark MM, Sloan JA, et al. Impacting quality of life for patients with advanced cancer with a structured multidisciplinary intervention: a randomized controlled trial. J Clin Oncol 2006;24:635-42.

31. Campbell A, Mutrie N, White F, et al. A pilot study of a supervised group exercise programme as a rehabilitation treatment for women with breast cancer receiving adjuvant treatment. Eur J Oncol Nurs 2005;9:56-63.

32. Courneya KS, Friedenreich CM, Quinney HA, et al. A randomized trial of exercise and quality of life in colorectal cancer survivors. Eur J Cancer Care 2003;12:347-57.

33. MacMillan F, Kirk A. Patterns of physical activity and the effect of accelerometer wear on physical activity participation in people with Type 2 diabetes. CARE 2010;3:6-22.

34. Broadhead WE, Gehlbach SH, de Gruy FV, et al. The Duke-UNC functional social support questionnaire. Measurement of social support in family medicine patients. Med Care 1988;26:709-23.

35. Freedson P, Bowles HR, Troiano R, et al. Assessment of physical activity using wearable monitors: recommendations for monitor calibration and use in the field. Med Sci Sports Exerc 2012;44:S1-4. 